\title{
TRIPÉ DA ESTRATÉGIA: O PAPEL DOS AGENTES INSTITUCIONAIS NO PROCESSO DE INTERNACIONALIZAÇÃO
}

\author{
Guilherme Zielinski Rodrigues, '1Silvio Luís de Vasconcellos \& Moema Pereira Nunes \\ Instituição Evangélica de Novo Hamburgo - IENH, Rio Grande do Sul, (Brasil) \\ Escola Superior de Propaganda e Marketing - ESPM, São Paulo, (Brasil) \\ Universidade FEEVALE, Rio Grande do Sul, (Brasil)
}

DETALHES DO ARTIGO
Histórico do Artigo:
Recebido em: 07 de agosto de 2020
Aceito: 21 de março de 2021
Disponível online: 30 de novembro de
2021
Sistema de revisão “Double blind review”
Editor Científico
Ilan Avrichir
Palavras-chaves:
Estratégia
Processo de internacionalização
Visão Baseada em Instituições
Tripé da Estratégia
Agentes institucionais

\section{INTRODUÇÃO}

O processo de internacionalização exige das empresas uma série de decisões complexas, muitas vezes envoltas em incertezas (Bradley et al., 2018; Fuentelsaz et al., 2019; Schweizer et al., 2010). Neste sentido, agentes institucionais se colocam em um papel de protagonismo para criar um sistema institucional fortalecido ou frágil, ao permitir ou não
Objetivo: compreender o papel dos agentes institucionais no processo de internacionalização, na perspectiva do tripé da estratégia.

Método: foi desenvolvido um estudo de caso único para investigar a internacionalização de cinco empresas que são associadas a um agente institucional, sob três categorias de análise - internacionalização sob a ótica econômica, comportamental e institucional.

Principais resultados: enquanto agente institucional, a entidade é crucial no processo de internacionalização de seus associados, a depender do porte e experiência exportadora. Na perspectiva econômica, coordena a identificação de novos mercados. Na comportamental, dinamiza o gradualismo de inserção internacional e constrói redes de relacionamento. $\mathrm{Na}$ institucional, desenvolve um ambiente colaborativo, legitimando a conversão de instituições informais em formais.

Relevância/originalidade: estudos empíricos sustentados pelo tripé da estratégia costumam limitar-se a categorizar os elementos recursos, indústria e instituições, separadamente. A perspectiva de análise a partir de agentes institucionais permite avaliar os efeitos das ações dos agentes institucionais de forma abrangente e inter-relacionada.

Contribuições teóricas/metodológicas: evidencia-se a inter-relação entre os elementos do tripé da estratégia, dinamizada por agentes institucionais de países emergentes. Agentes institucionais atuam como consolidadores de ações coletivas, reforçando seu papel na construção de instituições informais e formais, mitigando atos oportunísticos que poderiam vilipendiar ações coletivas na construção de confiança e facilitando o acesso a recursos e conhecimento.

Contribuições para a gestão: a pesquisa oferece uma oportunidade de reflexão sobre o posicionamento de entidades representativas setoriais que podem aprimorar suas ações em decorrência das contribuições percebidas pelos associados e os pontos de melhoria por eles identificados. o acesso a recursos e conhecimento que seriam por demais onerosos às empresas se optassem por atuar isoladamente e não por colaboração (Hidalgo et al., 2020).

$\mathrm{Na}$ perspectiva deste estudo, instituições representam o conjunto de regras e normas que moldam as ações de indivíduos ou organizações (North, 1990). Segundo Alexander (2005), agentes institucionais são atores responsáveis pelas

\footnotetext{
${ }^{1}$ Contato do autor E-mail: silvio.vasconcellos@espm.br
} 
interações entre os demais agentes e instituições no intuito de afetar a ação e o comportamento. Eles são essenciais para a conversão de normas, hábitos e práticas em objetos de intervenção deliberada do design institucional (Alexander, 2005). Em termos de perspectiva teórica, portanto, esse trabalho se situa na visão baseada nas instituições (Peng et al., 2009; Peng, 2002; Peng et al., 2008).

Embora o processo de internacionalização seja um vasto campo de estudos em negócios internacionais, desde as exportações indiretas até o investimento em plantas produtivas em mercados distantes (Osland et al., 2001), ainda há espaço para o entendimento de como os primeiros passos, no caso da exportação direta, possibilitam a consolidação de negócios internacionais de maneira duradoura (Dewald, 2016). Neste processo de consolidação da internacionalização via exportações, as práticas de negócios, suas regras e suas normas, bem como o compartilhamento de informações, passam a ser determinantes na formulação da estratégia (Monticelli et al., 2017). Neste sentido, a aplicação do tripé da estratégia permite a compreensão da inserção de economias emergentes em negócios globais (de Vasconcellos et al., 2012; Villan et al., 2020; Yamakawa et al., 2008). O tripé da estratégia, proposto por Peng (2002), parte do pressuposto que todas as empresas estão sob influência do ambiente institucional em que estão inseridas. Assim, a definição da estratégia resulta da análise da competição na indústria, dos recursos e capacidades específicos da firma e das condições e transições institucionais (Peng et al., 2008). Conforme destacado por Wang et al. (2012), não cabe mais questionar se o papel das instituições é relevante para a internacionalização das empresas, mas, sim, qual a importância das instituições neste processo, dado que esta influência é uma certeza.

Apesar de os estudos em negócios internacionais terem avançado ao buscar aproximar diferentes vertentes teóricas sob a perspectiva do tripé da estratégia, estudos empíricos sustentados por ele costumam limitar-se a categorizar os elementos recursos, indústria e instituições, separadamente (Gao et al., 2019), com base em recursos específicos (Su et al., 2016), a analisar a tomada de decisão pósentrada em mercados particulares (Xie et al., 2011) ou mesmo a identificar efeitos característicos de governança como as relações familiares dos sócios da empresa (Lahiri et al., 2020). A perspectiva de análise a partir de agentes institucionais que afetam o comportamento, potencialmente, que possam dinamizar os laços colaborativos dentro da indústria tem sido empregada para investigar a própria colaboração como estratégia (Hidalgo et al., 2020; Monticelli et al., 2017), porém sem que se avalie os efeitos sobre o processo de internacionalização de maneira abrangente e inter-relacionada com o foco sobre o papel do agente institucional.

Assim, o objetivo deste estudo é compreender o papel dos agentes institucionais no processo de internacionalização, na perspectiva do tripé da estratégia. Para essa compreensão, foram utilizados os três elementos do tripé da estratégia como categorias de análise. Depreende-se que, quando articulados, tais elementos podem oferecer condições específicas para a internacionalização, de maneira heterogênea, conforme seja possível articular os recursos já disponíveis na firma e os recursos acessíveis via agentes institucionais. Este estudo se justifica, teoricamente, por oferecer uma compreensão abrangente sobre como agentes institucionais facilitam o suporte industrial e institucional do tripé da estratégia, ao se combinarem com os recursos da firma. Como implicação gerencial, supõe-se que fazer parte de programas institucionalizados dentro da indústria oferecem diferentes condições para os seus associados, permitindo superar limitações cognitivas como a desconfiança em parcerias intraindústria e potencializar ações colaborativas.

Portanto, esse artigo contribui na literatura ao despertar o interesse sobre o papel do agente institucional no tripé a estratégia. Ele atua como integrador dos elementos do tripé, pois descreve seu papel de disseminador de informações de ordem econômica, complementador de recursos escassos nas organizações e como legitimador de ações coletivas de caráter institucional, tanto na sedimentação de instrumentos formais como na estruturação de laços informais entre exportadores sob a mesma associação setorial.

Por meio de um estudo de caso único, foram analisadas, via análise de conteúdo, cinco empresas associadas à Associação Brasileira das Indústrias de Máquinas e Equipamentos para os Setores do Couro, Calçados e Afins (ABRAMEQ), bem como a própria entidade para a compreensão de suas atividades em relação à promoção da internacionalização de seus associados. Entidades representativas de setores industriais têm sido investigadas regularmente como propulsoras de internacionalização (Fonte, 2019; Monticelli et al., 2018; Monticelli et al., 2017; Villan et al., 2020). A ABRAMEQ é uma entidade que, apesar 
de ser relativamente pequena, congrega outros agentes institucionais, o que a torna essencial para os seus 35 associados e, indiretamente, para os 120 fabricantes brasileiros de máquinas para a indústria coureiro-calçadista (Fonte, 2019). Além de atuar na internacionalização dessas empresas, como agente institucional em seu ramo de atuação, serve de suporte também para a inovação tecnológica e interface com organismos públicos. O mercado internacional de máquinas para calçados movimenta USD 38 bilhões anualmente e as empresas brasileiras representam aproximadamente um por cento desse montante (Fonte, 2019). Além disso, o caso se torna relevante para investigação por se tratar de uma área econômica que envolve tecnologia de ponta, em que as máquinas brasileiras rivalizam no exterior com concorrentes de economias mais avançadas tecnologicamente, como a Itália e a Alemanha, e muito competitivas em preços, como a vietnamita e a chinesa (Newark, 2021).

\section{REVISÃO DE LITERATURA}

Estudos sobre internacionalização, tradicionalmente, se detêm em duas perspectivas preponderantes: a racional-econômica e a comportamental. No entanto, com a maior inserção de empresas oriundas de mercados emergentes, uma terceira perspectiva ganhou destaque na última década, a visão baseada nas instituições (de Vasconcellos et al., 2012; Gao et al., 2019). A perspectiva do tripé da estratégia contribui com os estudos sobre negócios internacionais por permitir a integração de tais perspectivas (Peng et al., 2008).

\subsection{Estratégia e internacionalização}

A estratégia da firma, no contexto internacional, deve se basear em um plano para que ela se posicione de forma positiva em relação à concorrência e configure suas atividades de valor agregado em escala internacional (Cavusgil et al., 2010). A aceleração da globalização, a partir do final do século $X X$, aumentou a velocidade, a frequência e a magnitude com que as empresas de diversos segmentos acessam os mercados internacionais em busca de clientes, em especial as pequenas e médias empresas [PMEs] (Paul et al., 2017), ao desenvolver capacidades específicas para enfrentar a competição com concorrentes oriundos de contextos institucionais mais estáveis (Knight \& Kim, 2009).
Perante essa condição, os gestores de empresas buscam melhorar suas estratégias de internacionalização, visando a transformação de seus negócios em empreendimentos internacionalmente competitivos (Reuber et al., 2018).

Muitas empresas estabelecem as suas estratégias internacionais baseadas nas vantagens competitivas desenvolvidas em seus mercados domésticos (Fleury \& Fleury, 2007), usualmente no intuito de sedimentar o conhecimento do mercado através do acesso à informação confiável (Aguilera, 2011). Ao passo que crescem e obtêm ganhos em escala, em seus países de origem, elas acabam por desenvolver competências que se convertem em vantagens específicas (Fleury \& Fleury, 2007).

Estratégias internacionais precisam atender a, pelo menos, dois critérios de valor: (i) precisam explorar economias de escopo e (ii) devem dificultar o processo de imitação pela concorrência (Verbeke \& Kano, 2016). Ao adotarem estratégias internacionais, as empresas vislumbram a possibilidade de explorar oportunidades ambientais, ou então, neutralizar possíveis ameaças (Delios \& Henisz, 2003), supondo que a tomada de decisão se baseia em fatores racionalmente deliberados e no acesso pleno à informação (Aguilera, 2011; Dunning, 1988). Na perspectiva racional-econômica, o Paradigma Eclético, proposto por Dunning (1980, 1988), contribui no entendimento de como o investimento direto externo se desloca, numa constante busca por condições mais favoráveis. A primeira condição se refere à propriedade (ownership), a qual compreende a posse ou a capacidade de adquirir determinados ativos tangíveis ou intangíveis de modo mais efetivo que a concorrência. A segunda é a localização dos ativos (location), dado que os recursos podem estar situados em diferentes países e mercados, fazendo com que a empresa necessite avaliar se os custos de transação serão mais eficientes caso opte por localizar-se na região em que os recursos são mais acessíveis (Strange et al., 2009). A terceira condição é a internalização (internalization), que representa a capacidade de internalizar e transferir ativos para dentro da organização. O Paradigma Eclético, dentro da perspectiva racional-econômica, representa o modelo conceitual de explicação das operações internacionais das empresas mais disseminado e preconiza escolhas racionais decorrentes do acesso à informação e ao conhecimento do ambiente econômico, geralmente, relacionado a empresas multinacionais. 
Por outro lado, estratégias de internacionalização sob a perspectiva comportamental baseiam-se, essencialmente, na construção de recursos, conhecimento e redes de relacionamento, com destaque ao papel do empreendedor (Schweizer et al., 2010). Essa perspectiva está, basicamente, representada por três abordagens: (i) Modelo de Uppsala (Johanson, Vahlne, 1990; Johanson \& Wiedersheim-Paul, 1975; Johanson \& Vahlne, 1977), fundamentado nas teorias da firma e no comportamento organizacional, focalizado tanto no acúmulo gradual do conhecimento sobre os mercados estrangeiros, quanto, por consequência, no comprometimento crescente com esses mercados decorrente do constante aprendizado (Calixto et al., 2011) e experiência (Vahlne et al., 2017); (ii) networks, também desenvolvida por Johanson e Vahlne (1990, 2003), a partir do Modelo de Uppsala, por meio da adição dos relacionamentos como fator acelerador para atingir o mercado estrangeiro; e (iii), empreendedorismo internacional, considerada como linha de pensamento evolutiva dos seguidores do Modelo de Uppsala, com base nos estudos sobre o papel do empreendedor no processo de internacionalização e na tomada de decisão diante de incertezas (Schweizer et al., 2010; Vahlne et al., 2017).

Tais correntes teóricas, sejam elas baseadas na racionalidade econômica (Dunning, 1980, 1988) ou no comportamento do tomador de decisão diante de situações de incerteza (Johanson \& Vahlne, 2009), há décadas têm sustentado estudos sobre estratégias de internacionalização. Porém, o advento da entrada de novos protagonistas, oriundos de ambientes institucionais não vislumbrados pelas abordagens dominantes, ensejou estudos com base na teoria institucional, buscando meios de explicar a internacionalização de maneira mais abrangente, ao contemplar diferenças contextuais e as relacionando às diferenças entre os ambientes institucionais entre o país de origem e hospedeiro (Aguilera \& Grogaard, 2019; Cuervo-Cazurra, 2011; Peng et al., 2008). A partir desta interseção teórica, surgiu a visão baseada nas instituições, que sedimentou a perspectiva do tripé da estratégia aplicado aos negócios internacionais.

\subsection{0 tripé da estratégia}

O tripé da estratégia representa, metaforicamente, a combinação de três vertentes teóricas para embasar como os tomadores de decisão desenvolvem suas estratégias, combinando a visão baseada na indústria, a visão baseada em recursos e a visão baseada nas instituições (Peng, 2002). A visão baseada na indústria (Porter, 1980, 1991) considera que fatores externos, denominados forças, norteiam as definições estratégicas e permitem ações deliberadas, desenhadas a partir do planejamento. Essas forças são cinco, rivalidade dentro da indústria, poder de barganha dos compradores, poder de barganha dos fornecedores, ameaça de entrada de novos entrantes e ameaça de produtos e serviços substitutos. Tal análise resulta na determinação da posição menos vulnerável que a firma deliberadamente escolhe, em relação a esses fatores. Assim, o desempenho da organização depende de forma decisiva do grau de competitividade que a firma é capaz de construir para enfrentar as cinco forças exercidas sobre a indústria em que ela está inserida (Porter, 1980). Esse modelo descreve a estratégia competitiva como posicionamento da firma, tendo como objetivo maximizar atividades específicas, criando valor para os clientes e se distinguindo frente aos seus concorrentes (Porter, 1991).

Por outro lado, a visão baseada em recursos concede uma maior relevância às decisões e escolhas proativas da firma. Ainda que as oportunidades e ameaças sejam importantes, são os recursos seus únicos que encerram as variáveis-chaves que permitem o desenvolvimento e a sustentação de uma vantagem competitiva sustentável (Barney, 1995). Os recursos são os ativos tangíveis e intangíveis capazes de dotar a firma de capacidades que a torne competitiva (Barney, 1991). Assim, a gestão busca identificar e desenvolver os recursos significativos para um desempenho de nível superior, dando protagonismo ao papel do empreendedor na execução dessas tarefas (Fleury \& Oliveira Jr, 2001), por meio da habilidade de gerenciamento desses recursos em ambiente complexos, sujeitos à imprevisibilidade e à limitação da racionalidade humana (Barney \& Hansen, 1994).

Como terceira via, a visão baseada nas instituições alia as estratégias de internacionalização mais tradicionais - baseadas na indústria e em recursos comparando padrões institucionais dos ambientes de origem e de destino, o que Mike Peng denominou tripé da estratégia (Peng, 2002). Esta perspectiva, mais complexa, logo encontrou espaço em estudos de negócios internacionais (Krull et al., 2012; Peng et al., 2008; Peng \& Pinkham, 2009), em um momento em que as perspectivas tradicionais tinham 
dificuldade de explicar os efeitos do contexto institucional sobre a tomada de decisão e na definição de estratégias voltadas aos mercados internacionais, cada vez mais dinâmicos (Calixto et al., 2013). No entendimento de Ju et al. (2014), a utilização da visão baseada em instituições - de forma associada às outras duas visões - possibilita uma maior consistência na compreensão do processo de tomada de decisões na firma, principalmente quando da busca e entrada em mercados ainda desconhecidos. Permite, também, valer-se de laços de confiança estabelecidos a partir de interesses comuns entre clientes, fornecedores e, até mesmo, competidores (Fiedler et al., 2017) e possibilita a percepção de legitimidade do agente institucional como emulador de regras e de normas (Fuentelsaz et al., 2019; Kingston \& Caballero, 2009; Turcan \& Juho, 2014).

Na concepção de Peng et al. (2008), a visão baseada em instituições está centrada na interação dinâmica entre instituições e a firma, considerando as escolhas estratégicas como resultado de tal interação. Consequentemente, as escolhas estratégicas não são somente orientadas pela estrutura industrial e pela capacidade organizacional, mas também abarcam as restrições formais e informais exercidas por um quadro geral institucional específico, tanto no país de origem (Hitt, 2016) como no país hospedeiro (Petricevic \& Teece, 2019).

A visão baseada em instituições apresenta duas propostas essenciais. Na primeira, administradores e firmas buscam de forma racional seus interesses e definem suas escolhas estratégicas perante restrições institucionais (Peng et al., 2008). Na segunda, sustenta que, embora a mescla de instituições formais e informais oriente o comportamento da firma (Lynch \& Jin, 2016), em casos em que haja falha nas restrições formais, as restrições informais desempenham um papel relevante, mitigando incertezas e, por conseguinte, propiciando um ambiente mais estável aos administradores e às empresas (Ju et al., 2014).

A perspectiva do tripé da estratégia tem sido empregada em diferentes aspectos. Por exemplo, Gao et al. (2019) entendem que a escolha de localização de investimentos externos baseia-se na análise combinada da acessibilidade de recursos, contexto institucional e posicionamento na indústria. $\mathrm{Ju}$ et al. (2014) postulam que a governança de decisões relativas a exportações depende de como os fatores previstos no tripé da estratégia são avaliados pelos gestores. Por sua vez, Su et al. (2016) sugerem que a capacidade de acessar conhecimento de empresas multinacionais se dá pela combinação analítica da indústria, recursos e instituições. No contexto de clusters, Calixto (2013) avalia que segmentos industriais que fazem parte de cadeias globais de valor estão alicerçados na capacidade dos gestores interpretarem o ambiente institucional, o posicionamento na indústria e a capacidade de alavancar recursos.

\section{PROCEDIMENTOS METODOLÓGICOS}

No delineamento da pesquisa, optou-se pelo emprego de uma abordagem qualitativa por meio de um estudo de caso com uma perspectiva descritiva. A opção pelo estudo de caso único se justifica por ser uma estratégia de pesquisa centrada na compreensão da dinâmica presente em ambientes únicos (Eisenhardt, 1989) e pela possibilidade de revelar nuances específicas de um processo que inter-relaciona atores que buscam objetivos em comum (Yin, 1994), a partir de uma delimitação que revela a singularidade do caso (Strauss, 2004).

$\mathrm{Na}$ busca de atender ao objetivo de compreender o papel dos agentes institucionais no processo de internacionalização, na perspectiva do tripé da estratégia, a primeira delimitação necessária foi a escolha da entidade objeto de investigação. A escolha da ABRAMEQ atendeu a três critérios. Primeiro, tratase de uma entidade representativa de um setor internacionalizado quando comparado a outros setores produtores de máquinas industriais, em que o Brasil compete com produtores de economia mais avançadas, como Itália e Alemanha, revelando competitividade pelo aspecto industrial. Segundo, o setor de produção de máquinas para calçados atende a mais de 20 países (Fonte, 2019), o que coloca os fabricantes diante de cenários institucionais diversos e que precisam posicionar-se de forma sustentável, dado que as máquinas acarretam não só demanda por serviços como também garantia de assistência técnica. Terceiro, a ABRAMEQ possui vínculos institucionais com outro agente institucional de prestígio no Brasil e no exterior, a APEX BRASIL, agência de fomento à exportação do governo (APEX BRASIL, 2019), reunindo 27 de seus associados exportadores, através do projeto Machinery by Brasil (2020). Esse projeto, em seu escopo, congrega associados e é responsável por lançar diretrizes de ações institucionais que criem condições mais favoráveis no ambiente competitivo internacional. 
O estudo de caso, enquanto método de investigação, vale-se de mais de uma técnica de coleta de dados. Para Gil (2008), a obtenção de dados através de procedimentos múltiplos é fundamental para garantir a qualidade dos resultados, permitindo triangular as informações (Baxter \& Jack, 2008). Dados secundários contribuíram nesse processo por meio da consulta a relatórios setoriais e aos sites das empresas associadas, descritos na Tabela 1.

Tabela 1. Dados Secundários

\begin{tabular}{|c|c|}
\hline Item & descrição \\
\hline \multirow{13}{*}{$\begin{array}{c}1 \\
2 \\
3 \\
4 \\
5 \\
6 \\
7 \\
8 \\
9 \\
10 \\
11 \\
12 \\
13\end{array}$} & Site da ABRAMEQ \\
\hline & Site da Associada 1 \\
\hline & Site da Associada 2 \\
\hline & Site da Associada 3 \\
\hline & Site da Associada 4 \\
\hline & Site da Associada 5 \\
\hline & Site da APEX BRASIL \\
\hline & Site do projeto Machinery by Brasil \\
\hline & Relatório Anual 2017 - ABICALÇADOS \\
\hline & Relatório Setorial: Indústria de Calçados do Brasil 2017 \\
\hline & Perfil das Exportações de Calçados do Brasil 2017 \\
\hline & Pesquisa de Identificação de Benefícios - ABRAMEQ \\
\hline & Relatório de Inteligência Comercial (Brazilian Shoes + Leather Machinery) - ABRAMEQ \\
\hline
\end{tabular}

Fonte: Elaborado pelos autores

A ABRAMEQ é uma entidade setorial, sem finslucrativos, fundada em 1992, com o objetivo de promoção da união e desenvolvimento do setor nos mercados nacionais e internacionais (Machinery by Brasil, 2020). Com abrangência nacional, a ABRAMEQ possuía, em 2019, em torno de 35 empresas associadas, de um universo de cerca de 120 empresas brasileiras fabricantes de máquinas e equipamentos para o setor do couro e calçado. A ABRAMEQ desenvolve diferentes atividades a fim de internacionalizar seus associados, como participação em feiras e eventos, rodadas de negócios, missões comerciais e até a mesmo a criação de uma marca para a divulgação das máquinas brasileiras no exterior sob uma mesma bandeira.

Para compreender como a interação entre a entidade e seus associados acontece, foram realizadas seis entrevistas para triangular com os dados secundários. A quantidade de entrevistas foi determinada pela saturação dos dados (Hennink \& Kaiser, 2020). A coleta de dados na entidade ocorreu por meio de entrevista semiestruturada com um de seus gestores. Além da perspectiva da própria entidade, também foi preciso investigar a percepção de associados que se valem do seu capital intelectual. Foram entrevistados gestores de cinco empresas associadas. Percebeu-se que as estórias narradas pelos entrevistados atingiram um ponto de complementaridade e que novas entrevistas pouco poderiam acrescentar aos dados, uma vez que o universo de exportadores de máquinas de calçados associados à ABRAMEQ é de apenas 26 empresas, revelando a saturação prevista na literatura. $\mathrm{Na}$ Tabela 2 é apresentado o perfil de cada entrevistado e de suas empresas. 
Tabela 2. Perfil dos entrevistados

\begin{tabular}{c|c|c|c|c|c}
\hline Entrevistado & Cargo & Empresa & Fundação & $\begin{array}{c}\text { Início do processo de } \\
\text { internacionalização }\end{array}$ & $\begin{array}{c}\text { grau de } \\
\text { internacionalização* } \\
\text { (2017) }\end{array}$ \\
\hline Entr-1 & Gestor de Projetos & ABRAMEQ & 1992 & ------- & ------ \\
\hline Entr-2 & Diretor & Associado 1 & 1962 & Anos 1960 & $15 \%$ \\
\hline Entr-3 & Diretor Comercial & Associado 2 & 1972 & Anos 1990 & $21 \%$ \\
\hline Entr-4 & Diretor & Associado 3 & 1981 & Anos 1990 & $19 \%$ \\
\hline Entr-5 & Sócio proprietário & Associado 4 & 1998 & Não informado & $15 \%$ \\
\hline Entr-6 & Sócio proprietário & Associado 5 & 2007 & 2013 & $10 \%$ \\
\hline
\end{tabular}

(*) O grau de internacionalização é a razão entre total faturado e total exportado (Kafouros et al., 2008).

Fonte: Elaborado pelos autores

Antes de iniciar as entrevistas, os objetivos foram alinhados com o referencial teórico e as questões norteadoras foram elencadas no roteiro de entrevistas (Baxter \& Jack, 2008). Como havia entrevistas com associados e com o representante da ABRAMEQ, pequenas adequações foram feitas para atender o perfil do entrevistado, como sugerido por Moriarty (2011). Após concluídas, as entrevistas foram transcritas para que fossem analisadas em conjunto com os dados secundários por meio da aplicação da técnica de análise de conteúdo. Seguindo as orientações de Bardin (1977), foram definidas três categorias de análise: perspectiva econômica, perspectiva comportamental e perspectiva institucional. As entrevistas ocorreram em 2018, foram transcritas e as informações organizadas conforme as respectivas categorias. O resultado do processo de análise é apresentado a seguir.

\section{ANÁLISE DOS RESULTADOS}

4.1 Evidências da Internacionalização sob a ótica econômica

$\mathrm{Na}$ questão das vantagens de localização e, neste caso, como a entidade contribui com seus associados, o Entr-3, relata que em um passado recente houve a busca por novos mercados potenciais por meio de indicações da ABRAMEQ. Em um determinado momento, a entidade - através de um executivo de mercado - mapeou possíveis novos mercados e fez as indicações às empresas associadas. A partir do mapeamento, a empresa pôde prospectar novos clientes em países como África do Sul e Marrocos. Esta declaração alinha-se com que o propõe Dunning $(1980,1988)$ e (Fleury \& Fleury, 2007), que tratam da importância da localização na internacionalização por meio da abordagem econômica, estabelecida através de investigações embasadas em informações.

A ABRAMEQ se entende como parte relevante no que diz respeito às vantagens de localização. Segundo o Entr-1, a entidade tem a função de fomentar o acesso de seus associados ao mercado internacional, visto que a principal função da entidade é proporcionar alternativas de entrada nos principais mercados produtores de calçados. De acordo com ele, a inserção em novos mercados não ocorre somente por meio de ações comerciais; ela decorre de um estudo e um ranqueamento de possíveis mercados-alvo. A ideia é possibilitar aos associados a tomada de decisão com estratégia e inteligência comercial, evidenciando a relevância do acesso à informação no processo decisório de modos de entrada na internacionalização (Aguilera, 2011).

4.2 Evidências da Internacionalização sob a ótica comportamental

Com exceção da empresa Associada-1, que, segundo o Entr-2, é uma empresa exportadora desde o início de suas atividades, os outros entrevistados relataram que as vendas no mercado internacional iniciaram após alguns anos de trabalho no mercado doméstico. Quando a saturação do mercado interno foi percebida, iniciou-se a busca por alternativas para exportação, questão que converge com as proposições de Johanson e Vahlne (1977, 1990). Neste sentido, torna-se evidente que a participação da ABRAMEQ se fez relevante, já que ao participarem da entidade, as empresas associadas elevaram o seu nível de conhecimento, consolidaram sua orientação para o mercado externo e, assim, planejaram investimentos com vistas à exportação para novos mercados, o que repercute o papel da entidade como 
agente institucional, previsto na literatura (Alexander, 2005).

De acordo com o Entr-1, o acúmulo de conhecimento das empresas fabricantes de máquinas associadas à entidade é um dos pontos que levou essas empresas a buscarem o mercado internacional. Conforme ele, os associados da ABRAMEQ possuem condições de agregar valor às vendas de suas máquinas, pois através do conhecimento adquirido ao longo da história de cada empresa - somado ao conhecimento gerado pelo cluster calçadista onde estas organizações se encontram, o Vale do Sinos, no Rio Grande do Sul as empresas fabricantes de máquinas, sócias da ABRAMEQ, conseguem se destacar entre os outros concorrentes, principalmente, nos mercados latinoamericanos.

O Entr-5 justifica que o motivo principal para terem se tornado sócios da ABRAMEQ foi os contatos que poderiam buscar e explorar por meio da entidade. Para ele, o contato e a interação com outros fabricantes de máquinas só foi possível após terem ingressado no quadro de associados da entidade. Na opinião do Entr-5, esse contato foi importante para a sua empresa, pois possibilitou maior compreensão das atividades do mercado internacional. Complementa que o networking criado por meio da ABRAMEQ Ihes deu a possibilidade de prospectar clientes e the possibilitou fixar parcerias comerciais - com representantes - em países da América do Sul, o que seria inviável se dependesse de uma ação isolada da empresa.

$\mathrm{Na}$ formação de networking por meio da entidade e alinhado com a visão de internacionalização sob a ótica comportamental, o Entr-1 afirma que a ABRAMEQ possibilitou outros tipos de contatos e relacionamentos aos seus associados. Para ele, uma empresa associada à entidade tem a possibilidade de angariar recursos junto a APEX BRASIL, situação que não seria possível de forma individualizada. Desta maneira, a ABRAMEQ se tornou um elo entre fabricantes e órgãos do governo que provém recursos para ações comerciais internacionais, via projetos. A entidade também possibilitou, aos seus associados, contatos e interação com outros órgãos governamentais e com outras entidades de classe de indústrias dentro do cluster. Além disso, a ABRAMEQ viabilizou aproximações com entidades setoriais de outros países que facilitaram ações comerciais como feiras e missões - e com fabricantes de calçados de diferentes países latino-americanos, em rodadas de negócios. O comportamento das empresas analisadas está de acordo com a proposição defendida por Johanson e Vahlne (1990) quanto à importância dos relacionamentos, decorrente do envolvimento da firma junto às entidades, no que tange às relações no mercado externo.

Outro ponto a ser analisado dentro da perspectiva comportamental se refere à distância psíquica (Johanson \& Vahlne, 1977). Tem-se que a proximidade geográfica, de normas e de cultura são aspectos que influenciam no processo inicial de internacionalização da firma (Johanson \& Wiedersheim-Paul, 1975). Dentro desse cenário, agentes institucionais possibilitam aproximações que visam diminuir ou, quando não, eliminar tais barreiras. Foi evidenciado que a ABRAMEQ desenvolveu ações neste sentido. As empresas entrevistadas atuam, quase que em sua totalidade, nos países da América Latina, com menor distância psíquica. Porém, mesmo havendo certa proximidade - geográfica e cultural - com esses países, existe muitas diferenças e essas questões, por vezes, dificultavam e geravam temeridade nas empresas que buscavam exportar, no que a ABRAMEQ atuou como atenuante desses efeitos de aversão ao risco.

Para o Entr-4, a ABRAMEQ tem proporcionado, ao longo da sua existência, um encurtamento de distâncias - culturais e comerciais - de diferentes mercados aos seus associados. Exemplificou com as atividades comerciais de sua empresa no México, que se iniciaram por meio de missões comerciais desenvolvidas e executadas pela entidade. Salientou que, à época, ele não possuía conhecimento para atuar no mercado mexicano, havendo barreiras que dificultavam a tentativa de atividade naquele mercado. Foi por meio de iniciativas da ABRAMEQ mitigando as barreiras iniciais - que a Associada-3 pôde iniciar um trabalho naquele importante mercado produtor de calçados. Tal evidência indicou que a $A B R A M E Q$, enquanto agente institucional, atenuou efeitos comportamentais negativos, como distâncias psíquicas, recorrente em negócios internacionais quando a firma se defronta com cenários culturalmente incertos (Johanson \& Vahlne, 1990).

O Entr-3 também contribuiu na questão relativa às distâncias psíquicas e sobre o acesso a informações mais seguras para o planejamento de suas ações. Colocou que a entidade é peça importante no auxílio aos associados, principalmente na busca por novos mercados. Afirmou que já houve missões para o mercado da Índia, teoricamente apontado como de 
maior distância psíquica. Comentou que, em determinada ocasião, sua empresa buscou iniciar relações com mercado russo. Naquele projeto, não houve participação da entidade e a sua empresa atuou de forma individualizada. O projeto não prosperou e, segundo ele, a participação da ABRAMEQ em tal missão poderia ter aumentado as chances de sucesso da ação, pois o mercado da Rússia apresentava - e segue apresentando diferenças muito grandes em relação ao mercado brasileiro, situação difícil de ser transposta por uma empresa que atue de forma isolada. Evidenciou-se, portanto, que as empresas percebem a ABRAMEQ como facilitadora de ações planejadas, tanto alinhadas com uma perspectiva racional-econômica, na identificação de oportunidades (Aguilera, 2011) como responsável pela diminuição do distanciamento psíquico, alinhados com os pressupostos da perspectiva comportamental (Johanson \& Wiedersheim-Paul, 1975).

\subsection{Evidências da Internacionalização sob a ótica institucional}

O desenvolvimento deste estudo está ancorado no tripé da estratégia para análise de processos de internacionalização, de Peng et al. (2008), no qual a visão institucional é parte fundamental do processo de internacionalização, de forma integrada às visões econômica e comportamental. Conforme Calixto (2013), existe a possibilidade de as decisões estratégicas de uma firma - no que se refere à internacionalização - não estarem baseadas em único elemento do tripé, mas na combinação simultânea de dois, ou mais, elementos. Villan et al. (2020) constataram que os gestores consolidam informações, avaliam recursos disponíveis e os necessários e combinam esses elementos para interagir com entidades representativas da indústria para obterem desempenho superior.

Tal questão se torna evidente na fala do Entr-5, que salientou a relevância da formação - e utilização - do networking desenvolvido após terem se tornado associados da ABRAMEQ. Esse elemento pode ser avaliado por meio da visão baseada na indústria, dado que a entidade representa o setor, assim como pode ser entendido como uma interação com pessoas, oferecendo uma perspectiva a partir da visão baseada em recursos. Combinadas, possibilitam a interpretação via visão baseada nas instituições, quando se trata da disseminação de informações entre as empresas associadas pela entidade e, como relata a teoria, o estabelecimento de laços de confiança entre competidores (Fiedler et al., 2017).

Pôde-se perceber, por meio deste estudo, que o modo de inserção internacional das empresas é o mesmo. Todas as empresas trabalham com o mercado externo por meio das exportações, principalmente a exportação direta. Praticamente, todas as empresas entrevistadas - com exceção da Associada-5 - não dependem exclusivamente da ABRAMEQ para efetuarem contatos e vendas no mercado externo. Hoje, quatro das cinco empresas estudadas possuem autonomia para atuarem de forma independente no mercado internacional. Evidenciou-se, por meio das falas dos entrevistados, que a entidade não é algo essencial nas atividades internacionais das organizações. Aparentemente, o papel da ABRAMEQ mais relevante é na abertura de novos mercados, em que o grau de incerteza é mais elevado. Constatou-se que o trabalho da entidade não é primordial em um segundo estágio de trabalho no mercado internacional, principalmente após as empresas já terem iniciado a sua inserção internacional.

Observa-se que tal situação também está relacionada ao fato de boa parte das empresas analisadas já serem exportadoras quando do surgimento da entidade. Somente a Associada-4 e a Associada-5 foram fundadas após o surgimento da ABRAMEQ. Tais empresas já surgiram em um cenário diferenciado em relação aos demais associados na pesquisa e necessitaram fazer um esforço próprio em busca de mercados. Segundo o Entr-1, a entidade surgiu da união de algumas empresas durante a década de 1990, quando os fabricantes brasileiros de máquinas começaram a enfrentar concorrência externa devido à abertura do mercado nacional para bens de capital importados. Desta forma, segundo ele, com a perda de espaço no mercado interno, as empresas locais buscaram se organizar de forma coletiva para terem a oportunidade de ampliar - e fortalecer - o trabalho de exportação nos mercados latino-americanos. Observa-se, portanto, que as relações institucionais informais pré-existentes contribuíram no surgimento da ABRAMEQ, com vistas a união de forças para buscar alternativas de negócios de forma colaborativa, reforçando o papel dos agentes institucionais como propulsores de ações colaborativas entre os associados (Hidalgo et al., 2020).

Percebeu-se que a ABRAMEQ oportuniza um trabalho em rede e gera interações que reúnem 
aspectos colaborativos e competitivos entre os associados. Tal relação tem criado um ambiente propício ao desenvolvimento da coopetição, pois as empresas cooperam para criar valor, mas competem para dividir os resultados (Hidalgo et al., 2020; Monticelli et al., 2017), ao minimizar o comportamento oportunístico por parte das empresas envolvidas e ao reduzir a distância psíquica percebida pelos potenciais exportadores.

Porém, tal processo, na visão do Entr-3, ainda precisa ser aperfeiçoado. De acordo com ele, a entidade é fundamental em momentos que as empresas não possuem força de forma isolada em determinado mercado e que, em conjunto, via entidade, as empresas adquirem a representatividade necessária. Entretanto, salientou que a entidade precisa evoluir nesse quesito, pois, apesar do entendimento de que ela amplia as forças dos associados - quando estes atuam em conjunto ainda há falhas. Segundo ele, se faz necessário um amadurecimento por parte dos associados, para que possam tornar a entidade e suas ações mais fortes, já que, por vezes, alguns associados não compartilham informações e não possuem um espírito cooperativo, atuando de forma individualista dentro da entidade. Tanto a construção de legitimidade das ações conjuntas como a construção de confiança leva tempo (Fiedler et al., 2017) e depende do amadurecimento dos envolvidos, evidenciando aspectos institucionais informais e a fragilidade dos laços entre os envolvidos (Turcan \& Juho, 2014), por vezes dependentes da institucionalização de ações, via projetos.

Na visão do Entr-3, em alguns momentos, existe falhas da entidade. Para ele, por vezes, a ABRAMEQ não possui profundidade em suas atividades. No seu entendimento, tal fato ocorre pela falta de um executivo de negócios que pudesse ter maior aproximação do mercado internacional. Ainda, conforme ele, quando isto ocorre, os direcionamentos - em relação a mercados e ações passam a ser coordenados pelos próprios associados. São os associados, que nesses momentos de restrições, buscam, de forma coletiva, identificar e sugerir os mercados que desejam trabalhar, assim como, estabelecer - em conjunto - os formatos das ações que serão executadas, evidenciando a ação de instituições informais subjacentes à ação formal da ABRAMEQ.

A Tabela 3 sintetiza a verificação empírica das categorias de análise. Como se pode verificar, a entidade tem participação e está presente em grande parte das categorias investigadas. 
Tabela 3. Síntese dos elementos econômicos, comportamentais e institucionais em relação a ABRAMEQ

\begin{tabular}{|c|c|c|c|c|c|c|c|}
\hline \multirow{2}{*}{$\begin{array}{l}\text { Categoria de análise } \\
\text { (Elemento do tripé) }\end{array}$} & \multirow{2}{*}{$\begin{array}{c}\text { Componentes de } \\
\text { análise com base } \\
\text { na teoria }\end{array}$} & \multicolumn{6}{|c|}{ Verificação empírica } \\
\hline & & ABRAMEQ & Associada-1 & Associada-2 & Associada-3 & Associada-4 & Associada-5 \\
\hline \multirow[b]{4}{*}{ Ótica econômica } & Localização & Tem participação & Meios próprios & Entidade presente & Meios próprios & Entidade presente & Entidade presente \\
\hline & Internalização & $\begin{array}{ll}\text { Não } & \text { tem } \\
\text { participação } & \\
\end{array}$ & Meios próprios & Meios próprios & Meios próprios & Meios próprios & Sem evidência \\
\hline & Propriedade & Sem evidência & Sem evidência & Sem evidência & Sem evidência & Sem evidência & Sem evidência \\
\hline & $\begin{array}{l}\text { Evidências na } \\
\text { narrativa }\end{array}$ & 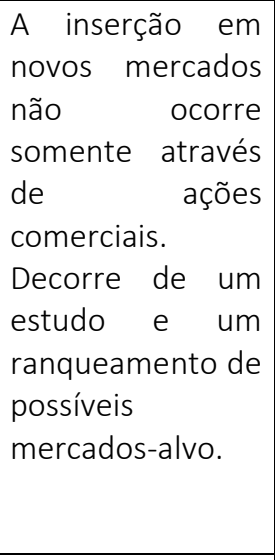 & $\begin{array}{l}\text { Possui um } \\
\text { representante } \\
\text { comercial na } \\
\text { Colômbia. }\end{array}$ & $\begin{array}{l}\text { Em passado } \\
\text { recente buscaram } \\
\text { novas } \\
\text { possibilidades de } \\
\text { mercado através } \\
\text { de indicações. }\end{array}$ & $\begin{array}{l}\text { Trabalha com uma } \\
\text { empresa de } \\
\text { representação no } \\
\text { mercado peruano. }\end{array}$ & 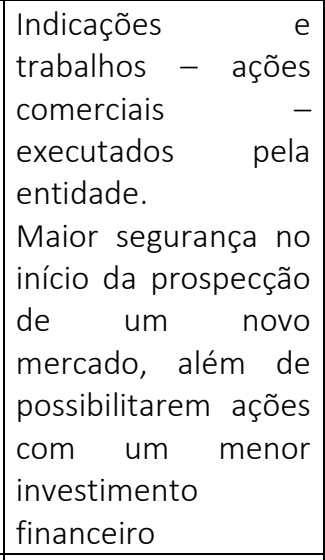 & $\begin{array}{l}\text { "Faz em torno de quatro } \\
\text { ou cinco anos que nós } \\
\text { estamos na ABRAMEQ e } \\
\text { este movimento faz } \\
\text { parte, mais ou menos, } \\
\text { de irmos um pouco mais } \\
\text { pra fora, mesmo no } \\
\text { Brasil e depois no } \\
\text { exterior" }\end{array}$ \\
\hline \multirow{4}{*}{$\begin{array}{c}\text { Ótica } \\
\text { comportamental }\end{array}$} & $\begin{array}{l}\text { Internacionalização } \\
\text { gradual (acúmulo } \\
\text { de conhecimento) }\end{array}$ & Tem participação & Sem evidência & $\begin{array}{l}\text { Com evidência / } \\
\text { Entidade presente }\end{array}$ & $\begin{array}{l}\text { Com evidência / } \\
\text { Entidade presente }\end{array}$ & $\begin{array}{l}\text { Com evidência / } \\
\text { Entidade presente }\end{array}$ & $\begin{array}{l}\text { Com evidência / } \\
\text { Entidade presente }\end{array}$ \\
\hline & $\begin{array}{ll}\text { Redes de } & \text { delacionamento } \\
\text { relnetworks) } & \\
\end{array}$ & Tem participação & $\begin{array}{l}\text { Entidade } \\
\text { presente }\end{array}$ & Entidade presente & Entidade presente & Entidade presente & Entidade presente \\
\hline & $\begin{array}{l}\text { Empreendedorismo } \\
\text { internacional }\end{array}$ & Sem evidência & $\begin{array}{l}\text { Com evidência / } \\
\text { Meios próprios }\end{array}$ & Sem evidência & Sem evidência & Sem evidência & Sem evidência \\
\hline & Distância psíquica & Tem participação & $\begin{array}{l}\text { Entidade } \\
\text { presente }\end{array}$ & Entidade presente & Entidade presente & Entidade presente & Entidade presente \\
\hline
\end{tabular}




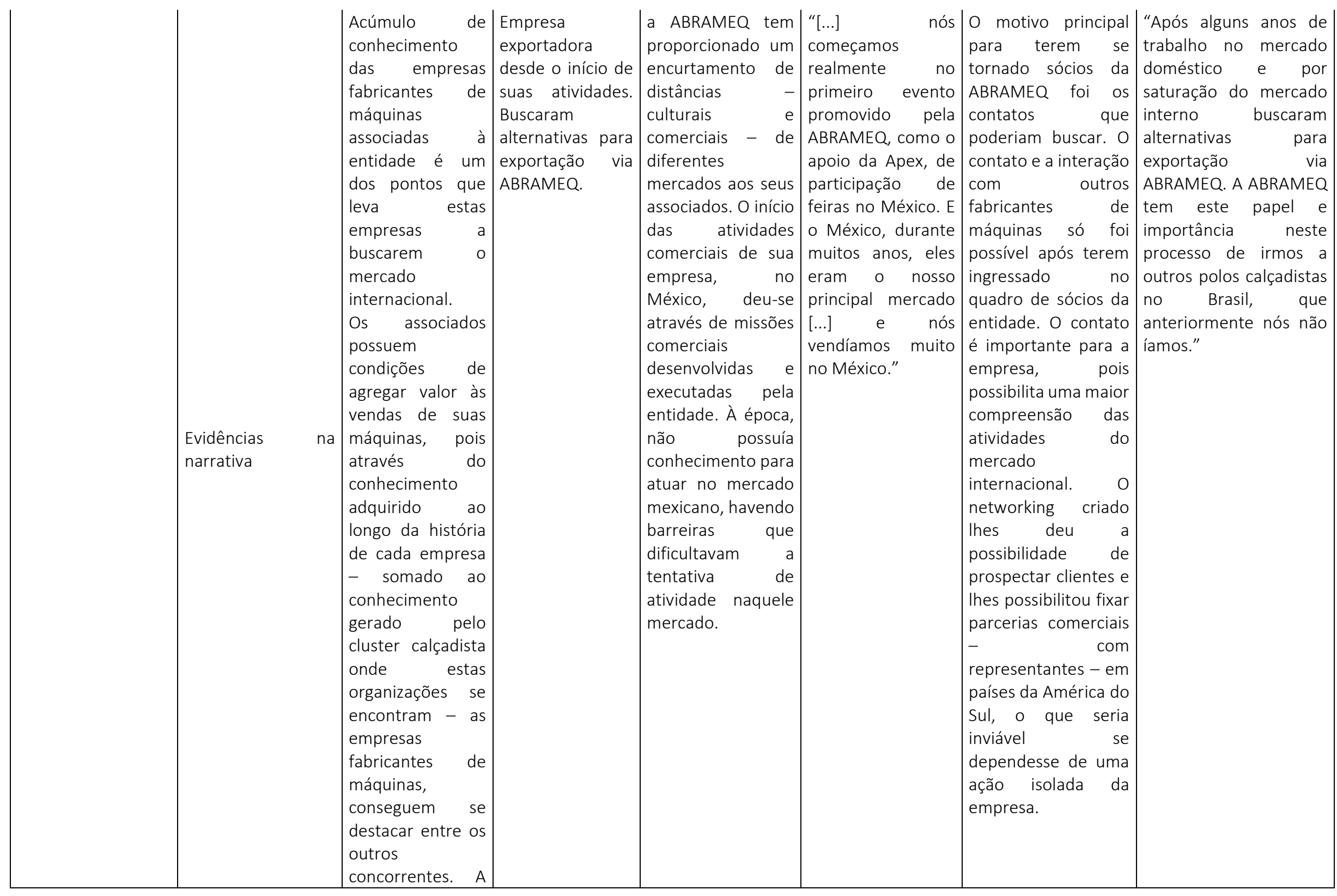

Internext | São Paulo, v.17, n. 1, p. 81-104, jan./abr. 2022 


\begin{tabular}{|c|c|c|c|c|c|c|c|}
\hline & & 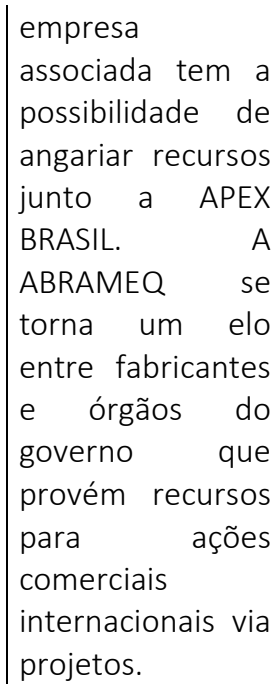 & & & & & \\
\hline \multirow[b]{5}{*}{ Ótica institucional } & $\begin{array}{l}\text { Networkings } \\
\text { (promoção de } \\
\text { informações) }\end{array}$ & Tem participação & $\begin{array}{l}\text { Entidade } \\
\text { presente }\end{array}$ & Entidade presente & Entidade presente & Entidade presente & Entidade presente \\
\hline & $\begin{array}{l}\text { Suporte a definição } \\
\text { de estratégias }\end{array}$ & Tem participação & $\begin{array}{l}\text { Entidade } \\
\text { presente }\end{array}$ & Entidade presente & Entidade presente & Entidade presente & Entidade presente \\
\hline & $\begin{array}{l}\text { Desenvolvimento } \\
\text { de ambiente } \\
\text { cooperativo }\end{array}$ & Tem participação & $\begin{array}{l}\text { Entidade } \\
\text { presente }\end{array}$ & $\begin{array}{l}\text { Entidade presente } \\
\text { (com restrição) }\end{array}$ & Entidade presente & Entidade presente & Entidade presente \\
\hline & $\begin{array}{l}\text { Instituições formais } \\
\text { e informais }\end{array}$ & Tem participação & $\begin{array}{l}\text { Entidade } \\
\text { presente }\end{array}$ & Entidade presente & Entidade presente & Entidade presente & Entidade presente \\
\hline & $\begin{array}{l}\text { Evidências } \\
\text { narrativa }\end{array}$ & $\begin{array}{lr}\text { As empresas } \\
\text { fabricantes de } \\
\text { máquinas para } \\
\text { calçados } \\
\text { buscaram } \\
\text { mercado externo } \\
\text { para tentarem } \\
\text { suprir a falta de } \\
\text { demanda rr no } \\
\text { enfrentada no } \\
\text { início dos anos } 90\end{array}$ & $\begin{array}{l}\text { A entidade não é } \\
\text { essencial nas } \\
\text { atividades } \\
\text { internacionais, } \\
\text { sendo } \\
\text { aparentemente o } \\
\text { papel da } \\
\text { ABRAMEQ mais } \\
\text { relevanter na } \\
\text { abertura de } \\
\text { novos mercados. }\end{array}$ & $\begin{array}{l}\text { A entidade é } \\
\text { fundamental em } \\
\text { momentos que as } \\
\text { empresas não } \\
\text { possuem força de } \\
\text { forma isolada em } \\
\text { determinado } \\
\text { mercado e que, em } \\
\text { conjunto, via } \\
\text { entidade, ras } \\
\text { empresas }\end{array}$ & $\begin{array}{l}\text { A ABRAMEQ é mais } \\
\text { relevante na } \\
\text { abertura de novos } \\
\text { mercados, em que } \\
\text { o grau de incerteza } \\
\text { é mais elevado. } \\
\text { Participação de } \\
\text { projetos com a } \\
\text { APEX BRASIL. }\end{array}$ & $\begin{array}{c}\text { Formação - e } \\
\text { utilização - de } \\
\text { networking } \\
\text { desenvolvido após } \\
\text { terem se tornado } \\
\text { sócios da ABRAMEQ. } \\
\text { Participação de } \\
\text { projetos com a APEX } \\
\text { BRASIL. }\end{array}$ & $\begin{array}{c}\text { "E em relação ao } \\
\text { mercado do exterior, } \\
\text { participar da ABRAMEQ } \\
\text { nos deu a oportunidade } \\
\text { de fazermos contato } \\
\text { com compradores } \\
\text { estrangeiros, } \\
\text { principalmente através } \\
\text { da FIMEC e projetos } \\
\text { desenvolvidos pela } \\
\text { entidade [...]" }\end{array}$ \\
\hline
\end{tabular}




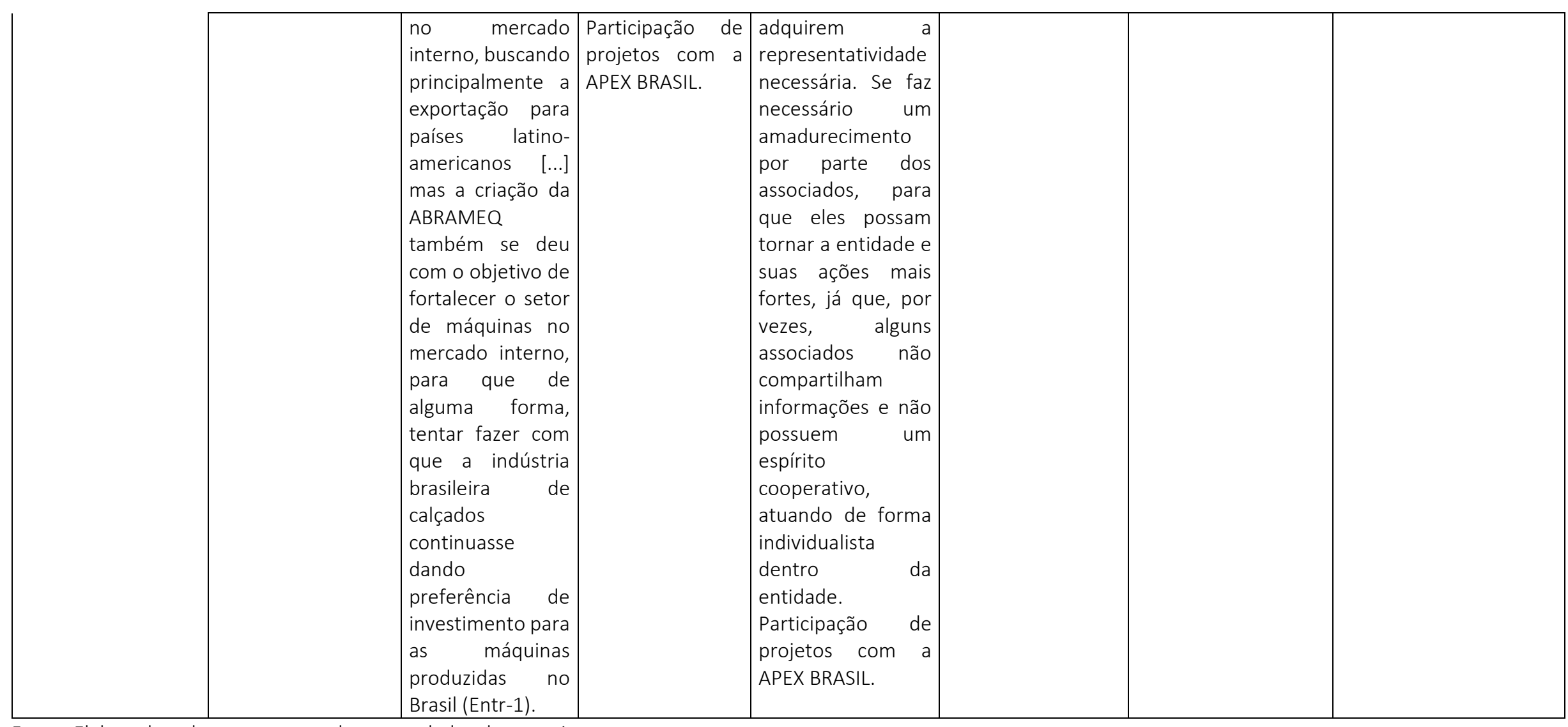

Fonte: Elaborado pelos autores com base nos dados da pesquisa. 


\section{DISCUSSÃO DOS RESULTADOS}

A análise dos resultados sob o olhar do tripé da estratégia, embora pretenda trazer uma contribuição holística sobre o processo de internacionalização, precisa ser feita, primeiramente, analisando cada um dos elementos formadores do tripé para entender como elementos econômicos, comportamentais e institucionais se relacionam (Gao et al., 2009).

\subsection{Internacionalização sob a ótica econômica}

A análise das entrevistas efetuadas e a confrontação com as informações secundárias evidencia que a internacionalização sob a ótica econômica possui um maior direcionamento às grandes empresas e as multinacionais. Como este estudo de caso único analisa cinco empresas que são de pequeno ou médio porte para compreender o papel de uma entidade de classe, muitos dos conceitos do Paradigma Eclético (Dunning, 1988) não seriam aplicáveis aos casos de internacionalização destas organizações, dado que PMEs possuem características próprias de tomada de decisão (Paul et al., 2017). Por consequência, as evidências oriundas do confronto da teoria com as informações extraídas das entrevistas seriam moderadas, visto que as empresas entrevistadas são exportadoras e não realizam investimentos diretos externos (Gao et al., 2009).

Entretanto, dada que a análise se refere ao papel do agente institucional, algumas questões podem ser identificadas e relacionadas no que tange à internacionalização das empresas vinculadas à entidade estudada e os conceitos propostos por Dunning (1980, 1988), no Paradigma Eclético. Percebeu-se que a ABRAMEQ adota, em parte, estratégias comuns a multinacionais, numa ótica racional-econômica. Em termos de vantagens de localização, percebe-se que a ABRAMEQ se faz relevante para algumas das empresas estudadas e permite superar as limitações predominantes em PMEs. De acordo com o Entr-5, por exemplo, em alguns momentos os mercados a serem explorados são definidos através de indicações e trabalhos ações comerciais - executados pela entidade. Por vezes, a entidade sugere quais são os países que oferecem possibilidades aos seus associados, trazendo, portanto, maior segurança no início da prospecção de um novo mercado, além de possibilitar ações com um menor investimento financeiro - já que a ABRAMEQ, ao indicar um mercado, normalmente, efetua atividades subsidiadas, pelo acesso a recursos que obtém com o acordo institucional junto à APEX BRASIL (Machinery by Brasil, 2020).

No caso dos aspectos relativos à internalização, do Paradigma Eclético, nota-se que algumas empresas se utilizam desta vantagem competitiva por meio de questões relativas à comercialização de seus produtos. A Associada-1, conforme relatos do Entr-2, possui um representante comercial na Colômbia. Já a Associada-2, segundo o Entr-3, tem um distribuidor de suas máquinas na Guatemala. Por sua vez, a Associada-3, de acordo com o Entr-4, trabalha com uma empresa de representação no mercado peruano. Tais ações comerciais externas representam, de certa forma, atividades de internalização alinhadas ao Paradigma Eclético (Dunning, 1980, 1988). A priori, a ABRAMEQ não apresenta sensíveis contribuições a seus associados neste quesito, dado que, como uma entidade setorial, não tem capacidade para internalizar atividades que gerem vantagens aos seus associados e não possui aptidão para desenvolver atividades comerciais - com real finalidade de venda - em outros países, a não ser a inteligência de mercado que repassa da APEX BRASIL. A limitação de evidências indica que nem mesmo a entidade é capaz de contribuir com as vantagens competitivas específicas de propriedade, permitindo-se inferir que uma leitura do caso a partir da ótica econômica, isoladamente, representaria uma limitação na análise do caso.

\subsection{Internacionalização sob a ótica comportamental}

Pôde-se averiguar que o modelo de internacionalização por meio da perspectiva comportamental tem maior aderência ao estudo de PMEs. Verifica-se, por meio do Modelo da de Uppsala que, normalmente, as empresas iniciam o processo de internacionalização das suas atividades com um nível de conhecimento muito baixo e com um alto nível de incerteza (Calixto, 2013) e passam por um processo de aprendizado contínuo (Calixto et al., 2011).

Com base no Modelo de Uppsala, percebe-se que a internacionalização das empresas ocorre de forma gradual - através do acúmulo de aprendizagem, conhecimento e experiência (Johanson \& Vahlne, 
1977). Assim, pôde-se averiguar que as empresas analisadas seguiram esse padrão para iniciarem suas atividades no mercado externo, expandindo atividades gradualmente, à medida em que aprendiam a lidar com mercados mais próximos psiquicamente.

Um segundo item que merece destaque são as redes de relacionamentos que se tornam acessíveis, via agente institucional. Quando uma empresa se internacionaliza, ela estabelece e se vale de uma rede de relacionamentos com clientes, fornecedores, distribuidores e outras entidades para continuar sua expansão internacional (Johanson \& Vahlne, 2003). No caso específico, também estabelece uma rede de relacionamentos com seus competidores do mercado externo, evidenciando ações coopetitivas, relatadas na teoria na comparação de comportamentos diferentes em mercados domésticos e internacionais (Monticelli et al., 2017). Para Johanson e Vahlne (1990), por meio da rede de relacionamentos, as empresas podem aprender com as demais organizações envolvidas na rede sobre as necessidades comuns, recursos específicos, estratégias e contextos que envolvem a atuação no mercado internacional. Assim, conectadas a uma rede de relacionamentos, as empresas podem adquirir experiência internacional de outras empresas, passando assim, a não ficarem dependentes somente da experiência e conhecimento próprios, o que, no caso, se evidencia pelas ações do agente institucional e, não, por ações deliberadas das empresas.

Pode-se afirmar que ABRAMEQ contribui na formação de uma rede de relacionamentos relevante. Entende-se que um dos pontos pelo qual a entidade é buscada por empresas fabricantes de máquinas seja o networking que ela proporciona aos seus associados com vistas a órgãos de fomento e outras entidades. No entanto, evidenciou-se que todas as empresas se valem do conhecimento gerado pelos contatos que são efetuados por meio da relação com os outros fabricantes associados, novamente respaldando a proposição do caráter crítico do agente institucional na dinamização do tripé da estratégia.

Outra questão que se buscou analisar dentro desta categoria foi o empreendedorismo internacional, com base em Schweizer et al. (2010). Porém, não foram identificadas evidências que pudessem ser destacadas e que, de fato, sinalizassem traços de empreendedorismo internacional. Também não se detectou, por parte das empresas associadas à $A B R A M E Q$, a busca primária de mercados mais longínquos em relação a mercados mais próximos. Tal questão poderia evidenciar o empreendedorismo internacional destas empresas. Porém, não foi possível evidenciar influências da ABRAMEQ em relação a esta possibilidade. Isto pode estar relacionado ao setor industrial em que o estudo foi desenvolvido, fabricação de máquinas, em que a internacionalização está vinculada a custos de frete e investimento de capital. No que tange ao alcance de mercados distantes de maneira mais rápida, como proposto por Cavusgil e Knight (2015), não foram encontradas evidências que pudessem fundamentar o empreendedorismo internacional nas ações da entidade e nem nas atividades de seus associados, mesmo havendo casos de internacionalização logo após a fundação da empresa.

Pode-se depreender que a entidade oferece contribuições a seus associados no processo de encurtamento de distâncias psíquicas. Além disso, constata-se que, na busca da internacionalização de seus associados e no planejamento de ações coletivas, a ABRAMEQ possibilita a detecção de fatores institucionais que afetam à internacionalização de seus associados, que dificilmente seriam percebidos isoladamente pelos associados se atuasse individualmente.

\subsection{Internacionalização sob a ótica institucional}

Mesmo evidenciada a inexistência de uma dependência plena dos associados em relação à entidade, é relevante o papel da ABRAMEQ na busca e seleção de mercados-alvos a serem prospectados. Desta maneira, se compreende que a entidade propicia suporte às empresas associadas ao revelar um suporte institucional relevante aos associados, que se reflete em ações relativas ao planejamento das empresas, integrando as perspectivas racionaleconômica e institucional, dois elementos do tripé da estratégia. Ainda, se pode entender que esta busca de mercados-alvo interfere nas estratégias das empresas associadas à entidade. Conforme Peng et al. (2008), a visão baseada em instituições está centrada na interação dinâmica entre instituições e firmas, levando em consideração as escolhas estratégicas resultantes destas interações.

A ABRAMEQ tem auxiliado seus associados na tomada de decisões e na busca de estratégias assertivas que ampliem as possibilidades de negócios no mercado internacional. O grupo de empresas que 
constituem a ABRAMEQ tem a oportunidade, em conjunto com a entidade de, anualmente, definir quais serão os mercados explorados e quais serão os formatos adotados nas ações e missões comerciais, como feiras, showrooms, projetos compradores, circuitos tecnológicos ou palestras. Tais projetos são documentados e, posteriormente, a entidade se encarrega de buscar recursos junto a APEX BRASIL para a efetivação e execução. A conversão de planos elaborados em colaboração em projetos que viabilizem o acesso a recursos governamentais evidencia o papel facilitador do agente institucional como emissor de ações institucionais formais (Hidalgo et al., 2020) e a institucionalização que transforma comportamentos e normas em regras e planos, em seu papel de agente institucional formal (Alexander, 2005).

O projeto Brazilian Shoes + Leather Machinery, fruto de uma iniciativa conjunta entre ABRAMEQ e APEX BRASIL, pode se enquadrar dentro de uma instituição formal. Tal projeto tem uma estrutura a ser seguida e cumprida pelas empresas associadas, uma vez que a APEX BRASIL estipula regras e critérios para o desenvolvimento das ações nele previstas. Todos os entrevistados enaltecerem o projeto, que tem por objetivos promover internacionalmente a indústria brasileira de máquinas para o setor coureiro-calçadista, possibilitar uma inserção internacional planejada, divulgar as empresas e seus produtos no exterior, disseminar informações de inteligência de mercado e reduzir custos para as atividades comerciais, quando comparado a iniciativas individuais. Nesse caso, a ABRAMEQ funciona com um elo entre o agente governamental e seus associados, caracterizando-se como um laço institucional formal, no que a ABRAMEQ tem o papel de legitimar ações institucionais. Essa legitimação é congruente com a percepção sobre como a visão institucional pode contribuir no entendimento da forma como as instituições formais são canalizadas em favor da internacionalização (Peng et al., 2008; Turcan \& Juho, 2014).

\section{CONSIDERAÇÕES FINAIS}

O presente estudo teve como objetivo compreender o papel dos agentes institucionais no processo de internacionalização, na perspectiva do tripé da estratégia. Para tanto, foi desenvolvido um estudo de caso em uma entidade setorial, a ABRAMEQ, e cinco empresas associadas. Dessas empresas, três delas já estão com uma base sedimentada no que tange o processo de internacionalização e possuem um significativo trabalho nos mercados estrangeiros. Entretanto, independentemente do nível de internacionalização das empresas estudadas, todas - de alguma maneira - se utilizam da estrutura e das ações desenvolvidas pela ABRAMEQ, em busca de diferentes níveis de recursos, principalmente no que tange à construção de relacionamentos e conhecimento.

Observou-se que existe similaridade com relação às ações internacionais. Para a maioria das empresas, a busca pela internacionalização se deu pela procura de novos mercados e pelo esgotamento do mercado interno - ou situações que ocorrem no mercado nacional, como crises, que demandaram novas estratégias comerciais. Cada empresa iniciou as suas atividades internacionais ao seu momento, mas se pode averiguar que a crise cambial, nos anos 1990, foi um fator determinante para ampliação da procura por novas oportunidades no mercado estrangeiro. A constituição da ABRAMEQ também foi crucial numa melhor estruturação, por parte das empresas, no seu processo de internacionalização, uma vez que a própria entidade foi criada neste período. Um fato marcante dentro desta análise mostra que quatro das cinco empresas iniciaram sua internacionalização após o amadurecimento da empresa no mercado doméstico.

Em termos teóricos, este estudo traz contribuições ao evidenciar a inter-relação entre os elementos do tripé da estratégia e apontar o papel crítico dos agentes institucionais de países emergentes. Evidenciou-se que os agentes institucionais atuam como consolidadores de ações coletivas, o que reforça o seu papel institucional, tanto informal quanto formal. A constatação do papel dos agentes institucionais na internacionalização de empresas já havia sido evidenciada na literatura (Hidalgo et al., 2020), porém, na forma como este estudo retrata, a interação se faz não só na geração de instrumentos formais que facilitam a internacionalização, mas também na construção de instituições informais que revelam o papel do agente institucional como elo de formação de relações entre empresas e vias complementares de reforço às perspectivas teóricas associadas ao tripé da estratégia. Na construção de instituições informais, os agentes institucionais atuam como balizadores de ações oportunísticas que poderiam vilipendiar ações coletivas que não construísse confiança (Fiedler et al., 2017), revelando o papel legitimador do agente 
institucional. Na implantação de instituições formais, facilitam o acesso a recursos e conhecimento, essenciais para o acesso a mercados internacionais.

Os resultados deste estudo também podem ter implicações para a ABRAMEQ e suas congêneres. Com o aporte teórico e com base nas informações colhidas junto aos associados, a entidade pode refletir sobre o seu posicionamento e utilizar deste estudo para aprimorar - e até mesmo inovar - em suas ações, dado que estão evidenciadas as contribuições de suas ações e os pontos de melhoria clamados pelos entrevistados.

Em relação às limitações deste trabalho, percebese que algumas são inerentes ao método. Embora quase um quinto dos participantes de projetos de internacionalização tenham sido entrevistados, não é possível assegurar que não haja outros fatores a serem explorados, que se configurem como específicos das outras empresas. Além disso, é possivel que peculiaridades de outros setores industriais provoquem efeitos diferentes numa análise do tripé da estratégia sobre o processo de internacionalização de seus associados. Contudo, constatou-se que a maioria das empresas estudadas (quatro de cinco) já possuem um nível de internacionalização considerável, o que, por vezes, dificultou a identificação da real participação e importância da ABRAMEQ no processo de internacionalização, dado que a experiência adquirida internacionalmente, mesmo que tenha sido via agente institucional, se internaliza no arsenal de conhecimento das empresas e propicia uma gradual autonomia em suas ações em mercados estrangeiros. É possível compreender que o papel da entidade no processo de internacionalização de empresas mais experientes e mais comprometidas com vendas ao exterior é mais focado na exploração de novos mercados, enquanto as novatas utilizam a entidade para aprender as etapas iniciais de internacionalização. Finalmente, o foco principal da pesquisa deteve-se em somente uma entidade. A análise de outras entidades e seus associados poderia contribuir pela comparação de resultados e elevar o nível de informações do estudo, trazendo, assim, mais evidências sobre a perspectiva multifacetada que o tripé da estratégia é capaz de oferecer.

Em termos de perspectivas para avanços teóricos nas pesquisas sobre internacionalização de empresas, este trabalho traz luz sobre o papel do agente institucional, ainda carente de avanços na literatura. Seu papel, embora crucial na dinamização do tripé da estratégia, possui grandes possibilidades de investigação, principalmente associados a temas como a complexidade institucional, focada em nuances econômicos e sociológicos dos estudos sobre instituições, como também para a ótica do policentrismo institucional, que procura entender as relações de poder existentes em ambientes institucionais complexos, como é o caso de mercados emergentes. Além disso, se mostra promissora a análise do papel combinado de agentes institucionais.

Os resultados aqui apresentados apresentam também potencial de se tornarem relevantes para empresários, diretores e executivos de empresas, que buscam compreender o processo de definição de estratégias internacionais, por meio do tripé da estratégia. Esta questão fica mais latente para as empresas de pequeno e médio porte, já que, por vezes, não possuem acesso à informação e dependem da experiência adquirida por competidores locais, situação em que as entidades associativas de setores específicos poderiam prestar serviços de grande relevância ao promover ações coordenadas entre competidores para atingir mercados externos. Por fim, este estudo evidencia que ações colaborativas, centradas em agentes institucionais, são capazes de potencializar o alcance das ações isoladas, colaborando com o planejamento de ações conjuntas entre competidores de um mesmo segmento industrial.

\section{REFERÊNCIAS}

Aguilera, R. (2011). Interorganizational Governance and Global Strategy. Global Strategy Journal, 95, 90-95. https://doi.org/10.1111/j.20425805.2011.00013.x

Aguilera, R. V. ., \& Grogaard, B. (2019). The dubious role of institutions in international business: A road forward. Journal of International Business Studies, 50(1), 20-35.

Alexander, E. R. (2005). Institutional Transformation and Planning: From Institutionalization Theory to Institutional Design. Planning Theory, 4(3), 209-223. https://doi.org/10.1177/1473095205058494

APEX BRASIL. (2019). APEX BRASIL. www.apexbrasil.gov.br 
Barney, J. B. (1991). Firm resources and sustained competitive advantage. Journal of Management, 17(1), 99-120.

Barney, Jay B. (1995). Looking inside for competitive advantage. The Academy of Management Executive, 9(4), 49-61.

Barney, Jay B., \& Hansen, M. H. (1994). Trustworthiness as a Source of Competitive Advantage. Strategic Management J, 15(S1), 175190. https://doi.org/10.1002/smj.4250150912

Baxter, P., \& Jack, S. (2008). Qualitative Case Study Methodology : Study Design and Implementation for Novice Researchers. The Qualitative Report, 13(4), 544-559.

https://doi.org/10.2174/1874434600802010058

Bradley, C., Hirt, M., \& Smit, S. (2018). Strategy to beat the odds. In McKinsey Quarterly (Issue February, pp. 1-11).

Calixto, C. V. (2013). Estratégias de internacionalização das empresas calçadistas brasileiras: uma análise sob as perspectivas da indústria, recursos e instituições.

Calixto, C. V., de Souza, Y. S., de Vasconcellos, S. L., \& Garrido, I. G. (2011). Uma análise sobre o conceito de aprendizagem na perspectiva de internacionalização da escola nórdica. Internext Revista Eletrônica de Negócios Internacionais Da ESPM, 6(1), 1-20.

Calixto, C. V., Garrido, I. L., de Vasconcellos, S. L., \& Monticelli, J. M. (2013). Estratégias de internacionalização das empresas calçadistas: análise sob a perspectiva da indústria, capacidades organizacionais e instituições. Revista Alcance, 20.

Cavusgil, S. Tamer, Knight, G., \& Riesenberger, J. R. (2010). Negócios internacionais: estratégia, gestão e novas realidades. Pearson Prentice Hall.

Cavusgil, S.T., \& Knight, G. (2015). The born global firm: An entrepreneurial and capabilities perspective on early and rapid internationalization. Journal of International Business Studies, 46(1), 3-16. https://doi.org/10.1057/jibs.2014.62
Cuervo-Cazurra, A. (2011). Global Strategy and Global Business Environment : the Direct and Indirect Influences of the Home Country on a Firm 'S Global Strategy. Global Strategy Journal, 20, 16-21. https://doi.org/10.1111/j.2042-5805.2011.00035.x

de Vasconcellos, S. L., Calixto, C. V., Garrido, I. L., \& de Souza, Y. S. (2012). A dependência de trajetória em negócios internacionais. BASE - Revista de Administração e Contabilidade Da Unisinos, 9(3), 306-315. https://doi.org/10.4013/base.2012.93.08

Delios, A., \& Henisz, W. J. (2003). Political hazards, experience, and sequential entry strategies: The international expansion of Japanese firms, 19801998. Strategic Management Journal, 24(11), 11531164. https://doi.org/10.1002/smj.355

Dewald, J. (2016). Achieving longevity: How great firms prosper through entrepreneurial thinking. In Achieving Longevity: How Great Firms Prosper Through Entrepreneurial Thinking. University of Toronto Press. https://www.scopus.com/inward/record.uri?eid=2s2.085006733669\& partnerID $=40 \& \mathrm{md} 5=b 6 \mathrm{~d} 025 \mathrm{eba}$ e83b5635a4873dc3b8c0dd7

Dunning, J. H. (1980). Toward an eclectic theory of international production. The International Executive, 22(3), 1-3. https://doi.org/10.1002/tie.5060220301

Dunning, J. H. (1988). The Eclectic Paradigm of International Production: A Reinstatement and Some Possible Extensions. Source Journal of International Business Studies, 19(1), 1-31. https://doi.org/10.2307/154984

Eisenhardt, K. M. (1989). Building Theories from Case Study Research. Academy of Management Review, 14(4), 532-550. https://doi.org/10.5465/amr.1989.4308385

Fiedler, A., Fath, B. P., \& Whittaker, D. H. (2017). Overcoming the liability of outsidership in institutional voids: Trust, emerging goals, and learning about opportunities. International Small Business Journal, 35(3), 262-284. https://doi.org/10.1177/0266242616662510

Fleury, A., \& Fleury, M. T. L. (2007). Internacionalização e os países emergentes. Atlas. 
Fonte, V. R. da. (2019). Estratégia de comunicação para a promoção do setor de máquinas para calçados no continente americano - um caso da ABRAMEQ Associação Brasileira das Indústrias de Máquinas e Equipamentos para os Setores do Couro, Calçados e Afins. Instituto Politécnico de Leiria.

Fuentelsaz, L., González, C., \& Maicas, J. P. (2019). Formal institutions and opportunity entrepreneurship. The contingent role of informal institutions. BRQ Business Research Quarterly, 22(1), 5-24. https://doi.org/10.1016/j.brq.2018.06.002

Gao, G. Y., Murray, J. Y., Kotabe, M., \& Lu, J. (2009). A "strategy tripod" perspective on export behaviors: Evidence from domestic and foreign firms based in an emerging economy. Journal of International Business Studies, 41(3), 377-396. https://doi.org/10.1057/jibs.2009.27

Gao, Q., Li, Z., \& Huang, X. (2019). How EMNEs choose location for strategic asset seeking in internationalization? Chinese Management Studies, 13(3), 687-705. https://doi.org/10.1108/CMS-062018-0573

Hennink, M. M. ., \& Kaiser, B. N. (2020). Saturation in Qualitative Research. In P. Atkinson, S. Delamont, A. Cernat, J. W. Sakshaug, \& R. A. Williams (Eds.), SAGE Research Methods Foundations. SAGE Publications Ltd. https://doi.org/10.4135/9781526421036822322

Hidalgo, G., Monticelli, J. M., Pedroso, J., Verschoore, J. R., \& de Matos, C. A. (2020). The Influence of Formal Institution Agents on Coopetition in the Organic Food Industry. Journal of Agricultural \& Food Industrial Organization. https://doi.org/10.1515/jafio-2019-0009

Hitt, M. A. (2016). International strategy and institutional environments. Cross Cultural \& Strategic Management, 23(2), 206-215. https://doi.org/10.1108/ccsm-11-2015-0168

Johanson, Jan; Vahlne, J.-E. (1990). The mechanism of internationalisation. International Marketing Review, 7(4), 11-24.

Johanson, J.;, \& Wiedersheim-Paul, F. (1975). The Internationalization of the firm - Four Swedish Cases. The Journal of Management Studies, October, 305-322.
Johanson, J., \& Vahlne, J. (2003). Business Relationship Learning and Commitment in the Internationalization Process. Journal of International Entrepreneurship, 1, 83-101.

Johanson, J., \& Vahlne, J. (2009). The Uppsala internationalization process model revisited: From liability of foreignness to liability of outsidership. Journal of International Business Studies, 40(9), 1411-1431. https://doi.org/10.1057/jibs.2009.24

Johanson, Jan;, \& Vahlne, J.-E. (1977). The Mechanism of Internationalisation. International Marketing Review, 7(4), 11-24. http://jama.jamanetwork.com/article.aspx?doi=10.1 001/jama.1915.02580170024007

Johanson, Jan, \& Vahlne, J.-E. (1977). Process of the Internationalization Development Firm-a Model of Knowledge Foreign and Increasing Market Commitments. Journal of International Business Studies, 8(1), 23-32. https://doi.org/10.1057/palgrave.jibs.8490676

Ju, M., Zhao, H., \& Wang, T. (2014). The Boundary Conditions of Export Relational Governance: A "Strategy Tripod" Perspective. Journal of International Marketing, 22(2), 89-106. https://doi.org/10.1509/jim.13.0114

Kafouros, M. I. ., Buckley, P. J. ., Sharp, J. A. ., \& Wang, C. (2008). The role of internationalization in explaining innovation performance. Technovation, $28,63-74$.

Kingston, C., \& Caballero, G. (2009). Comparing theories of institutional change. Journal of Institutional Economics, 5(2), 151-180. https://doi.org/10.1017/\$1744137409001283

Knight, G. A., \& Kim, D. (2009). International business competence and the contemporary firm. Journal of International Business Studies, 40(2), 255273. https://doi.org/10.1057/palgrave.jibs. 8400397

Krull, E., Smith, P., \& Ge, G. L. (2012). The internationalization of engineering consulting from a strategy tripod perspective. The Service Industries Journal, 32(7), 1097-1119. https://doi.org/10.1080/02642069.2012.662758 
Lahiri, S., Mukherjee, D., \& Peng, M. W. (2020). Behind the internationalization of family SMEs: A strategy tripod synthesis. Global Strategy Journal, 10(4), 813-838. https://doi.org/10.1002/gsj.1376

Lynch, R., \& Jin, Z. (2016). Exploring the institutional perspective on international business expansion: Towards a more detailed conceptual framework. Journal of Innovation and Knowledge, 1(2), 117-124. https://doi.org/10.1016/j.jik.2016.01.001

Machinery by Brasil. (2020). Machinery by Brasil. Machinery by Brasil. Machinery by Brasil

Monticelli, J.M., Garrido, I. L., \& de Vasconcellos, S. L. (2018). Coopetition and institutions: a strategy for Brazilian wineries facing internationalization. International Journal of Wine Business Research, 30(1). https://doi.org/10.1108/IJWBR-08-2016-0028

Monticelli, Jefferson Marlon;, Calixto, C. V., de Vasconcellos, S. L., \& Garrido, I. L. (2017). The influence of formal institutions on the internationalization of companies in an emerging country. Review of Business Management, 19(65), 358-374. https://doi.org/10.7819/rbgn.v0i0.3040

Moriarty, J. (2011). Qualitative methods overview. Qualitative Research Methods A Data Collectors Field Guide, 2005(January), 1-12. http://www2.Ise.ac.uk/LSEHealthAndSocialCare/rese arch/NIHRSSCR/methodsreviews.aspx

Newark, N. J. (2021). the global footwear manufacturing machines market is expected to grow from USD 17.23 billion in 2017 to USD 25.67 billion by 2025 at a CAGR of 5.1\% during the forecast period from https://www.globenewswire.com/newsrelease/2020/02/24/1989435/0/en/GlobalFootwear-Manufacturing-Machines-Market-isExpected-to-Reach-USD-25-67-Billion-by-2025-FiorMarkets.html

North, D. C. (1990). Institutions, Institutional Change and Economic Performance. In Institutions, Institutional Change and Economic Performance. Cambridge University Press. https://doi.org/10.1017/CBO9780511808678
Osland, G. E., Taylor, C. R., \& Zou, S. (2001). Selecting international modes of entry and expansion. Marketing Intelligence \& Planning, 19(3), 153-161. https://doi.org/10.1108/02634500110391690

Paul, J., Parthasarathy, S., \& Gupta, P. (2017). Exporting challenges of SMEs: A review and future research agenda. Journal of World Business, 52(3), 327-342. https://doi.org/10.1016/j.jwb.2017.01.003

Peng, M. W. (2002). Towards an Institution-Based View of Business Strategy. Asia Pacific Journal of Management, 19, 251-267.

Peng, M. W. ., Sun, S. L., Pinkham, B., \& Chen, H. (2009). The Institution-Based View as a Third Leg for a Strategy Tripod. Academy of Management Perspectives, 23(3), 63-81. https://doi.org/10.5465/amp.2009.43479264

Peng, M. W., \& Pinkham, B. (2009). The Institution-Based View as a Third Leg for a Strategy Tripod. Academy of Management Perspectives, 23(3), 63-81.

https://doi.org/10.5465/AMP.2009.43479264

Peng, M. W., Wang, D. Y. L., \& Jiang, Y. (2008). An institution-based view of international business strategy: A focus on emerging economies. Journal of International Business Studies, 39(5), 920-936. https://doi.org/10.1057/palgrave.jibs.8400377

Petricevic, O., \& Teece, D. J. (2019). The structural reshaping of globalization: Implications for strategic sectors, profiting from innovation, and the multinational enterprise. Journal of International Business Studies, 50(9), 1487-1512. https://doi.org/10.1057/s41267-019-00269-x

Porter, M. E. (1980). Competitive Strategy. Free Press.

Porter, M. E. (1991). Towards a dynamic theory of strategy. Strategic Management Journal, Winter(12), 95-117.

Reuber, A. R., Knight, G. A., Liesch, P. W., \& Zhou, L. (2018). International entrepreneurship: The pursuit of entrepreneurial opportunities across national borders. In Journal of International Business Studies (Vol. 49, Issue 4). https://doi.org/10.1057/s41267018-0149-5 
Schweizer, R., Vahlne, J.-E., \& Johanson, J. (2010). Internationalization as an entrepreneurial process. Journal of International Entrepreneurship, 8(4), 343370. https://doi.org/10.1007/s10843-010-0064-8

Strange, R., Filatotchev, I., Buck, T., \& Wright, M. (2009). Corporate governance and international business. Management International Review, 49(4), 395-407. https://doi.org/10.1007/s11575-0090001-z

Strauss, A. (2004). 15 Methods of Data Analysis in Qualitative Research. Analysis, 3(3), 1-32. https://doi.org/10.1136/ebn.3.3.68

Su, Z., Peng, M. W., \& Xie, E. (2016). A Strategy Tripod Perspective on Knowledge Creation Capability. British Journal of Management, 27(1), 58-76. https://doi.org/10.1111/1467-8551.12097

Turcan, R. V., \& Juho, A. (2014). What happens to international new ventures beyond start-up: An exploratory study. Journal of International Entrepreneurship, 12(2), 129-145. https://doi.org/10.1007/s10843-014-0124-6

Vahlne, J. E., Hamberg, M., \& Schweizer, R. (2017). Management under uncertainty - the unavoidable risk-taking. Multinational Business Review, 25(2), 91109. https://doi.org/10.1108/MBR-03-2017-0015
Verbeke, A., \& Kano, L. (2016). An internalization theory perspective on the global and regional strategies of multinational enterprises. Journal of World Business, 51(1). https://doi.org/10.1016/j.jwb.2015.08.014

Villan, W. J., Garrido, I. L., \& de Vasconcellos, S. L. (2020). Estratégia e Desempenho pela Perspectiva do Tripé da Estratégia. Revista de Negócios, 25(3), 7491.

Wang, C.; Hong, J.; Kafouros, M.; Wright, M. (2012). Exploring the role of government involvement in outward FDI from emerging economies. Journal of International Business Studies, 43, 655-676.

Xie, Y. H., Zhao, H. J., Xie, Q. J., \& Arnold, M. (2011). On the determinants of post-entry strategic positioning of foreign firms in a host market: A "strategy tripod" perspective. International Business Review, 20(4), 477-490. https://doi.org/10.1016/j.ibusrev.2010.09.005

Yamakawa, Y., Peng, M. W., \& Deeds, D. L. (2008). What Drives New Ventures to Internationalize from Emerging to Developed Economies? Entrepreneurship Theory and Practice, 1(972), 59-82.

Yin, R. K. (1994). Case study research: design and methods (2nd ed.). Sage Publications, Inc. 
Guilherme Zielinski Rodrigues - Instituição Evangélica de Novo Hamburgo - IENH, Rio Grande do Sul, (Brasil). E-mail: guilherme zielinski@hotmail.com

Silvio Luís de Vasconcellos - Escola Superior de Propaganda e Marketing - ESPM, São Paulo, (Brasil). E-mail: silvio.vasconcellos@espm.br Orcid id: https://orcid.org/0000-0002-9986-679X

Moema Pereira Nunes - Universidade FEEVALE, Rio Grande do Sul, (Brasil). E-mail: moemanunes@hotmail.com Orcid id: https://orcid.org/0000-0002-9729-9074

\title{
STRATEGY TRIPOD: THE ROLE OF INSTITUTIONAL AGENTS IN THE INTERNATIONALIZATION PROCESS
}

\author{
Guilherme Zielinski Rodrigues, Silvio Luís de Vasconcellos \& Moema Pereira Nunes \\ Instituição Evangélica de Novo Hamburgo - IENH, Rio Grande do Sul, (Brasil) \\ Escola Superior de Propaganda e Marketing - ESPM, São Paulo, (Brasil) \\ Universidade FEEVALE, Rio Grande do Sul, (Brasil)
}

\begin{tabular}{l}
\hline ARTICLE DETAILS \\
\hline Article history: \\
Received: 07 august 2020 \\
Accepted: 21 march 2021 \\
Available online november: 30 th 2021 \\
Double Blind Review System \\
Scientific Editor \\
Ilan Avrichir \\
\hline Keywords \\
Strategy \\
Internationalization process \\
Institution-based view \\
Strategy tripod \\
Institutional agents
\end{tabular}

\begin{abstract}
Objective: To understand the role of institutional agents in the internationalization process from the perspective of the strategy tripod.

Method: A single case study was developed to investigate the internationalization of five companies that are associated to an institutional agent, under three categories of analysis - internationalization from economic, behavioral, and institutional perspectives.
\end{abstract}

Main results: As an institutional agent, the studied entity is crucial to the internationalization process of its associates, depending on the size and export's experience. From an economic perspective, it coordinates the identification of new markets. In behavioral, it dynamizes the gradualism of international insertion and building relationship networks. In the institutional, it develops a collaborative environment, legitimizing the conversion of informal institutions into formal ones.

Relevance/originality: Empirical studies supported by the strategy tripod are usually limited to categorizing the elements of resources, industry, and institutions separately. The perspective of analysis from institutional agents allows to evaluate the effects of their actions in a comprehensive and interrelated way.

Theoretical contribution: The interrelation between the elements of the strategy's tripod is evidenced, promoted by institutional agents from emerging countries. Institutional agents act as consolidators of collective actions, reinforcing their role in building informal and formal institutions, mitigating opportunistic acts that could vilify collective actions in building trust and facilitating access to resources and knowledge as well.

Managerial contributions: The research offers an opportunity to reflect on the positioning of sectorial representative entities that can improve their actions, given that the contributions perceived by members and the points of improvement identified and highlighted by them 


\title{
TRÍPODE DE LA ESTRATEGIA: EL PAPEL DE LOS AGENTES INSTITUCIONALES EN EL PROCESO DE INTERNACIONALIZACIÓN
}

\author{
Guilherme Zielinski Rodrigues, Silvio Luís de Vasconcellos \& Moema Pereira Nunes \\ Instituição Evangélica de Novo Hamburgo - IENH, Rio Grande do Sul, (Brasil) \\ Escola Superior de Propaganda e Marketing - ESPM, São Paulo, (Brasil) \\ Universidade FEEVALE, Rio Grande do Sul, (Brasil)
}

\begin{tabular}{l} 
DETALLES DEL ARTÍCULO \\
\hline Historia del Artículo: \\
Recibido: 07 de agosto de 2020 \\
Aceptado: 21 de marcha de 2021 \\
Disponible en línea: 30 de noviembre 2021 \\
Double Blind Review System \\
Editor Científico \\
Ilan Avrichir \\
\hline Palabras-clave: \\
Estrategia \\
Proceso de internacionalización \\
Visión con base en las instituciones \\
Trípode de estrategia \\
Agentes institucionales
\end{tabular}

\section{RESUMEN}

Objetivo: Comprender el papel de los agentes institucionales en el proceso de internacionalización, desde la perspectiva del trípode estratégico.

Método: Se desarrolló un estudio de caso único para investigar la internacionalización de las cinco empresas que se asocian a un agente institucional, bajo tres categorías de análisis - la internacionalización de las perspectivas económicas, de comportamiento e institucionales.

Principales resultados: Como agente institucional, la entidad estudiada es fundamental para el proceso de internacionalización de sus asociados, dependiendo del tamaño y experiencia exportadora. Desde una perspectiva económica, coordina la identificación de nuevos mercados. En conductual, dinamiza el gradualismo de inserción internacional y la construcción de redes de relación. En lo institucional, desarrolla un ambiente colaborativo, legitimando la conversión de instituciones informales en formales.

Relevancia/originalidad: Los estudios empíricos respaldados por el trípode de estrategia generalmente se limitan a categorizar los elementos de recursos, industria e instituciones por separado. La perspectiva de análisis desde agentes institucionales permite evaluar los efectos de las acciones de los agentes institucionales de forma integral e interrelacionada.

Aporte teórico: Se evidencia la interrelación entre los elementos del trípode de la estrategia, promovida por agentes institucionales de países emergentes. Los agentes institucionales actúan como consolidadores de acciones colectivas, reforzando su rol en la construcción de instituciones formales e informales, mitigando actos oportunistas que puedan vilipendiar las acciones colectivas para generar confianza y facilitar el acceso a recursos y conocimientos.

Aportes gerenciales: La investigación ofrece una oportunidad para reflexionar sobre el posicionamiento de las entidades representativas sectoriales que pueden mejorar sus acciones como resultados de las contribuciones percibidas por los miembros y los puntos de mejora identificados y destacados por ellos.

\section{Como citar este artigo:}

Rodrigues, G. Z., de Vasconcellos, S. L., \& Nunes, M. P. (2022). Tripé da Estratégia: O Papel dos Agentes Institucionais no Processo de Internacionalização. Internext, 17(1), 81-104. https://doi.org/10.18568/internext.v17i1.622 